\title{
CONTEMPLACIÓN «ENTRE PUCHEROS»
}

DOI: https://doi.org/10.52039/seminarios.v61i214.173

IRENE GUERRERO*

En la iconografía teresiana encontramos abundantemente la representación de las diversas gracias místicas recibidas por la santa: el rostro arrobado mientras su mano sostiene la pluma ante el libro abierto, o un ángel que la atraviesa con un dardo, o distintas visiones que ella misma cuenta en sus escritos. Pero la imagen más curiosa es, sin duda alguna, ver a la mística doctora no con la pluma ni con ángeles alrededor, sino con la sartén en la mano, en la cocina conventual, eso sí, con el rostro también arrobado.

Pucheros y contemplación podrían parecer en principio términos antagónicos, pero en Teresa todo es posible, todo se puede armonizar, pues es la gran experta en entretejer lo celestial y lo divino. Cuenta de ella una monja contemporánea, Isabel de santo Domingo, que la descubrió alguna vez en la cocina asaltada por esa Presencia que la hacía paralizarse justo en el momento en que estaba cocinando. A la monja, acostumbrada ya a ver a la Madre Teresa en dicho trance, lo que más le preocupó fue que se cayera el poco aceite que había y ese era todo su cuidado.

Esta imagen junto a la famosa frase de santa Teresa: «entre los pucheros también anda el Señor» ( $F, 5-8)$, serán el telón de fondo de este artículo que pretende exponer una espiritualidad que es alimento para nuestra vida cotidiana. La bien llamada "Madre de los espirituales» en esta ocasión nos va a enseñar, sartén en mano, que a Dios se le encuentra allá donde se cuece la historia, o sea, en nuestra vida cotidiana.

La propuesta de Teresa de Jesús en estos momentos es la siguiente: por una parte, la de volver a cuidar el huerto interior, descubrirlo, atenderlo y valorar lo que perdura en el tiempo para poder recoger los frutos de lo auténtico, de lo que verdaderamente alimenta la vida, frente a tantas corrientes espirituales que prometen llegar a la plenitud en quince días; por la otra, atender esa vida cotidiana, esos «pucheros», entre los que el Señor anda y nos sale al encuentro. Lo que

* Irene Guerrero es carmelita descalza en el convento de San José de Toro (Zamora). En el 2009 publicó su primera novela, inspirada en la vida de la beata Isabel de la Trinidad (Elisabeth Catez), carmelita descalza de Dijon: Voy a la luz, al amor, a la vida. En 2014 ha publicado una biografía novelada sobre Santa Teresa: Teresa de Jesús, la dama herida. Asidua colaboradora en la revista «Teresa de Jesús». En estos últimos años se dedica a la formación de novicias y junioras en su comunidad. 
se propone Teresa no es tanto enseñarnos a hacer un rato de oración como a formar personas orantes, para ello será necesario reconstruir el corazón y eso posiblemente nos ayude a ser personas nuevas para un mundo nuevo que todos deseamos.

\section{El hUERTO: tRABAJO INTERIOR}

En una sociedad en crisis económica como la nuestra, resulta interesante ver cada vez con más frecuencia el retorno de algunas personas a labrar la tierra, una tierra que hasta el día de ayer fue despreciada. No son pocos los que están recuperando la heredad de sus abuelos y vuelven a sembrar, ayudando a revalorizar así los productos naturales y sanos en los llamados huertos ecológicos frente a una comida industrializada, fruto del consumismo y de una sociedad en stress permanente que no tiene tiempo de nada.

$\mathrm{Si}$ es cierto que muchas de nuestras enfermedades se deben a una mala alimentación también podemos considerar que la salud del alma se debilita de igual manera por falta de una buena nutrición espiritual y por muchos descuidos. Tal vez no seamos del todo conscientes de la «basura» que echamos en nuestro interior y que poco a poco va destruyendo nuestra vida espiritual. Nos podemos sorprender, con un buen análisis, de los bajos niveles que registramos a veces en esperanza, en entusiasmo, en fe.

Por eso, antes de meternos «entre los pucheros» hay que procurar los ingredientes, que sean sanos y de calidad. Para ello, Teresa también es partidaria de volver a la propia tierra, la del corazón, a esa parcela que echamos muchas veces en olvido: "Ha de hacer cuenta el que comienza, que comienza a hacer un huerto en tierra muy infructuosa, que lleva muy malas hierbas, para que se deleite el Señor» (V 11, 6).

Es necesario, por tanto, preparar la tierra, labrarla, escoger las semillas, sembrar y recoger los frutos, es decir: arrancar malas costumbres, pensamientos negativos, deseos ambiguos, frivolidades; examinar el corazón, labrarlo para que no sean las emociones y sentimientos los que nos dominen, discernir las semillas de lo que queremos plantar, pues no todo cabe, no todo vale; plantar nuevos hábitos (por ejemplo: dedicar todos los días un rato de oración, a la misma hora, en el mismo sitio; cuidar lecturas que nos alimenten, no solo que nos distraigan). $Y$ después regar estas simientes con el amor y la constancia, cuidar que no se sequen o que no se ahoguen por las malas hierbecillas que pueden estragarlo todo. Se nos descubre entonces que hay mucha tarea por delante, que todo esto no se hace en dos días sino que es una labor lenta y arduas.

Según la santa, nos hemos ido lejos de lo que es nuestro centro, de nuestra tierra. Como hijos pródigos nos vamos y machacamos la herencia, exprimimos de mala manera la vida, pensando que mientras más cosas tengamos más felices seremos y luego andamos mendigando aquí y allá lo que nadie puede dar- 
nos. Tan lejos nos vamos que dice que el alma, «para que torne a tomar amor a estar en su casa es menester mucho artificio, y si no es así, poco a poco, nunca haremos nada» $(C 26,10)$.

Parece como si Teresa se arremangase y se pusiera el mandil invitándonos a trabajar, a no confiar en soluciones rápidas, fáciles y engañosas: ¡manos a la labor!, nos dice (una expresión suya muy conocida). Es necesario, hoy más que nunca, saber que la vida espiritual hay que alimentarla, sostenerla y que solo así podremos disfrutar de los frutos a su tiempo. Pero hemos de sacudirnos de nuestras perezas, de nuestras inercias y determinarnos de una vez por todas, siendo cada vez más conscientes de nuestra necesidad: «Pedid luz, porque estamos ciegos y con hastío para no poder comer los manjares que os han de dar vida, sino los que os han de llevar a la muerte» (C 30, 3).

El huerto era un lugar importante para esta mujer, maestra de oración. Recordamos que en su casa había un huerto y en él jugaba ella de pequeña con su hermano. Cuando funda san José, su primer convento, se preocupará de mandar construir ermitas en la huerta. En otro lugar dice que siempre le dio recreación el ver campo, flores, agua.

Es una recomendación que encontramos con frecuencia para sus fundaciones, que tengan vistas y huerto. Al padre Gracián con la nueva casa de Villanueva, le escribe diciendo: «Estoy con cuidado, que creo ni tiene vistas ni campo» (Carta 371, 1).

De la imagen del huerto va a sacar ella ese tratadillo de oración en el que nos describe todo un proceso del orante con las cuatro maneras de regarlo. Cuando lo regamos con los calderos que sacamos del pozo será «a mayor trabajo nuestro», es el tiempo del esfuerzo personal, de una meditación en sequedad, sin gustos espirituales; el regar con la ayuda de una noria se hará luego más fácil, pues ya la persona va teniendo más recursos y está más avanzada en el camino espiritual. El río será un grado más adelante, es la etapa en que la comunicación con Dios, la relación con Él, se hace mucho más sencilla y natural y experimentamos cómo el agua de su gracia va invadiendo nuestra tierra reseca. Pero nada será comparable al agua de lluvia, es aquí donde verdaderamente conocemos la plena gratuidad de Dios sin nada de esfuerzo por nuestra parte.

El huerto es un espacio donde aprendemos a meditar, a conectar con nuestro interior, aprendiendo profundas lecciones sobre la vida y sobre la muerte. Cualquier cosa que le puede ocurrir a un huerto o a un jardín, le puede ocurrir también al alma: demasiada agua o demasiado poca, calor, tormentas, granizo, plagas, muerte de las raíces, florecimiento, maduración, belleza, productividad.

Es un lugar para recrearse, pero sobre todo es un lugar de trabajo intenso en el que plantamos, arrancamos, enterramos, regamos, cosechamos. Al fin y al cabo, el trabajo en ese huerto va a ser lo que sostenga la casa, entendida esta como espacio de vida, esa casa que hemos de construir sobre la Roca para que nada la pueda destruir. 
Basándonos en lo que dice Teresa, que el cimiento es la oración, deducimos que el huerto será el símbolo de esa labor que hemos de realizar si queremos recoger frutos para nuestro sustento. Un trabajo que es personal, pues cada uno tiene su trocito de tierra, su parcela; y es también insustituible, nadie puede suplirnos en esa labor. Todos hemos de trabajar para ayudar a la economía familiar (comunidad, congregación, Iglesia), para conservar el patrimonio y hacerlo crecer.

Es un trabajo que abarca desde el conocimiento propio, pasando por el desasimiento y otras virtudes, hasta llegar a obtener las flores y los frutos ya maduros que después podremos compartir con otros. Es también el trabajo interior en el que aprendemos el ciclo vital que es VIDA-MUERTE-VIDA. Y vamos adquiriendo la sabiduría interior de que todo brote que apunta, toda experiencia, toda relación, toda etapa, vive y luego muere para luego volver a vivir de otra manera, transformada ${ }^{1}$.

Aprendemos entonces a observar las lunas, el viento, las nubes. Todo eso que nos afecta al corazón y que nos es necesario para este trabajo que nos han propuesto. Para esto es importante que desarrollemos nuestra capacidad de atención: viendo, concentrándonos, contemplando. Una mirada atenta nos puede conducir a una vida profunda mientras nos va alejando de la superficialidad barata y engañosa. A veces pasamos por la vida sin fijarnos realmente en todo lo que está aconteciendo a nuestro lado, en todo lo que se nos va regalando a través de las personas, la naturaleza, las cosas. Nos perdemos en muchas ocasiones la bondad de una mirada, la belleza de una puesta de sol o la caricia que Dios nos hace cada día. Son realidades que existen y no les prestamos atención.

Aprendemos también a podar en los tiempos que son, porque no cualquier tiempo es conveniente, y con ello nos olvidarnos de las prisas, de la eficiencia inmediata y de la ansiedad.

Aprendemos a regar, a saber qué plantas necesitan más agua. A regar con el esfuerzo de sacar calderos del pozo cuando no llueve. No podemos quedarnos ahí, mirando al cielo, a ver si cae alguna gota, y cuando nos cansamos de ver que no cae nada, nos vamos a otra cosa, a entretenernos un poco, porque eso de sacar agua puede ser demasiado pesado. Llegarán las lluvias y será muy sin trabajo, pero las lluvias no son eternas. Llegará el verano y nos ponemos a regar o en un momento se nos secará todo. A veces también regaremos con el río, siendo ese árbol plantado al borde de la acequia.

Todo esto se irá aprendiendo por observación y por consulta a otros más expertos que entienden de esa tierra del corazón. Pero al final cavar, regar, ir

1. Teresa desarrolla esta idea sobre todo hablando del gusano de seda que se transforma en mariposa: «Crecido este gusano..., comienza a labrar la seda y edificar la casa donde ha de morir... Pues, ea, hijas mías, priesa a hacer esta labor y tejer este capuchillo quitando nuestro amor propio y nuestra voluntad, el estar asidas a ninguna cosa de la tierra... Muera este gusano como lo hace en acabando de hacer para lo que fue criado, y veréis cómo vemos a Dios y nos vemos tan metidas en su grandeza como lo está este gusanillo en este capucho» $(5 \mathrm{M} 2,4.6)$. 
quitando un día y otro las hierbecillas es cosa nuestra. Nadie puede suplir nuestro trabajo, el que se nos ha encomendado, del que somos responsables.

Vamos así adquiriendo la verdadera sabiduría. Vamos haciéndonos expertos, como nos anima Teresa a ser. Ella está convencida de que todos estamos capacitados para tener experiencia de Dios. Hay quienes van al huerto para dar un paseo, o solo trabajan en él los fines de semana. Pero así nunca se harán expertos. Hemos de ir todos los días, siempre sobre él. Y esto, según Teresa, requiere:

Constancia. Exige de nosotros un trabajo constante. No nos vale unos días intensos, como los días de Ejercicios, si luego lo descuidamos y dejamos crecer la hierba por todos lado. Es la «determinada determinación», eligiendo no abandonar la tarea: «venga lo que viniere... trabajase lo que se trabajare... siquiera llegue allá, siquiera muera en el camino o no tenga corazón para los trabajos que hay en él, siquiera se hunda el mundo».

Paciencia. Es lo más difícil. Hay que tener mucha paciencia para ver salir los frutos, para no tirar de los brotes, queriéndolos abrir a la fuerza, que es algo del todo inútil. A veces también podemos precipitarnos y arrancar sin saber discernir el trigo de la cizaña. Quisiéramos quitar de nosotros todo lo que creemos que nos estorba, como corregir un defecto, suavizar el carácter o no sentir la envidia. Nos puede pasar que deseamos un cambio en nosotros y al primer intento nos hundimos por no conseguirlo. Teresa nos enseña que la exigencia también es paciente, «poco a poco», repetirá ella: «así que no os apretéis, porque si el alma se comienza a encoger, es muy mala cosa para todo lo bueno» $(C 41,5)$.

Es aceptar que todo este proceso interior ha ser lento, que así son las cosas de la tierra y así es el alma. Se va echando raíces, se va creciendo, muchas veces «sin saber cómo».

Integración. Se trata de saber integrar lo que va aconteciendo, las sorpresas de la vida, los dolores, las experiencias negativas, que serán ese abono que necesitamos y que hay que saber aprovechar para que las plantas crezcan más y mejor. Todo lo que acontece forma parte de nuestro proceso interior, de todo podemos aprender, porque el Señor se nos cuela a través de todas las circunstancias y, como dice Juan de la Cruz, él ordena todo para nuestro bien.

Soledad. El trabajo del hortelano o del agricultor es un trabajo siempre en soledad. Uno no se puede distraer con otros. Alguna vez se nos puede echar una mano, pero esto es como lo de las vírgenes prudentes y necias, que ninguna puede evadir su propia responsabilidad.

Sí que nos animará el ver cómo otros trabajan con entusiasmo, y eso nos edificará. Cuando llegue el tiempo de la recolección podremos recoger cantando y compartir. En cambio, mientras cavamos, quitamos hierbas, podamos, regamos con el agua del pozo, imposible estar a otra cosa.

A veces la soledad será deseada y "sonora», otras será una «soledad poblada de aullidos», según el salmo, una soledad temible que también hemos de afrontar alguna vez, sin huir de ella. 
Silencio. Este será el que nos ayude a echar raíces profundas en Cristo. El que nos forzará al límite del amor. No podemos trabajar, cuidar de todo esto si estamos de cháchara todo el día, si nuestra atención está dispersa en mil cosas, si no acabamos de centrarnos, de amar ese silencio, ese del "callado amor», o si necesitamos continuamente buscar alivios en esta tensión. Los hortelanos saben que el trabajo los confina a un silencio productivo. En ese silencio será donde las palabras van madurando poco a poco, y en lugar de ofrecer palabras vanas, las daremos maduras y con algún sentido.

Todos estos puntos serán comunes para los que queremos responsabilizarnos de nuestra vida y comenzar un viaje interior que nos llevará muy lejos. Pero vivimos con otros. Formamos una comunidad, una parroquia, vamos juntos en este camino. Por eso hemos de tener en cuenta que no todos producimos lo mismo, que no todos los frutos son iguales. Y ahí será la riqueza. Lo bonito del huerto es que en cada parcela hay algo diferente, hay hortalizas, hay flores, hay frutales... y todo será necesario. Aquí entra el tema de la comparación y también de la envidia. Es lo que dice Teresa con las que quieren ser contemplativas y no se conforman con el camino que el Señor les va marcando. Cada uno tiene su tierra y cada tierra es apta para ciertos frutos. Yo no puedo tratar unas plantas igual que otras. Hemos de aprender a valorar lo que cada uno hace, a encontrar todo hermoso, necesario y saludable: «Porque no está esto en vuestro escoger, sino en el del Señor... Dejad hacer al Señor de la casa; sabio es, poderoso es, entiende lo que os conviene y lo que le conviene a Él también» $(C 17,7)$.

Lo importante es que en el huerto de nuestra alma nos encontremos con el Señor. Todo trabajo va encaminado a esto: para encontrarnos con Él, producir los frutos que Él quiere y ser enviados también por Él.

\section{LOS INGREDIENTES DE TERESA}

Una vez que tenemos el huerto de nuestra alma en producción, podemos hablar de algunos ingredientes básicos que no pueden faltar en el recetario de Teresa de Jesús; sin ellos no podemos cocinar ni para nosotros ni para los demás, y de lo que se trata es de esto, de ir poniendo entre todos la mesa, una mesa de inclusión en la que todos quepan, una mesa siempre presidida por Cristo.

Pero para cocinar lo primero que hay que tener es fuego y saberlo vigilar, cuidando que no se nos apague. A veces nos olvidamos de esta vigilancia, de añadir combustible y remover. Teresa nos recomienda echar de vez en cuando algunas «pajitas» para avivar este fuego, que no son otra cosa que tener algunos deseos y pensar «qué se hará por quien tanto debe» ( $V 15,7)$, y también, «procurando perder de nuestro derecho en muchas cosas» (V 31, 22).

Quienes recordamos con gusto aquella película de hace varios años, El festín de Babette, pudimos comprobar cómo quienes se sientan a una mesa bien preparada en todos sus detalles, no sólo se benefician a sí mismos con el ali- 
mento sino que sus vidas y sus relaciones pueden cambiar en el transcurso de la cena; se pueden desbloquear muchas barreras interiores que fueron puestas hace mucho tiempo; se pueden ver verdades que se ignoraron; se pueden caer prejuicios y abrir posibilidades nuevas con las que ya no se contaba.

Los ingredientes bien combinados que nos brinda Teresa nos alimentan y a la vez devuelven la salud a nuestra alma herida y por mucho tiempo mal cuidada.

\section{Conocimiento propio}

Es lo básico, lo más cotidiano, lo que no puede faltar. Dice la santa que es «el pan con el que se han de comer todos los manjares»(V13, 15). Hemos de conocernos, no solo para descubrir nuestros fallos y lo poco que podemos sino también para saber cuán grande es nuestra capacidad de Dios y lo mucho que podemos recibir si a ello nos disponemos.

Conocerse es llamar a las cosas por su nombre, sin miedos, sin caretas que nos oculten nuestro verdadero rostro. Saber quién soy yo, qué quiero y a dónde me dirijo. Pero sobre todo, descubrir que no nos recibimos de nosotros mismos sino que somos recibidos de Otro, porque, como bien dice Teresa, «no nos imaginemos huecos en lo interior» (C 28, 10). Conocerse es saberse habitado.

Este conocimiento propio no lo vamos a adquirir fundamentalmente leyendo libros de autoayuda. Según Teresa, lo logramos mirándole a Él, donde se ven las verdades, donde nos vemos tal cual somos: «A mi parecer, jamás nos acabamos de conocer, si no procuramos conocer a Dios; mirando su grandeza, acudamos a nuestra bajeza y mirando su limpieza veremos nuestra suciedad; considerando su humildad veremos cuán lejos estamos de ser humildes» $(1 \mathrm{M} 2,9)$.

Esta manera de conocerse que nos enseña Teresa de Jesús tiene la ventaja de que no nos deja ensimismarnos mirándonos solamente a nosotros mismos, porque si así fuera estaríamos «metidos siempre en la miseria de nuestra tierra», dando vueltas a lo que nos pasa o nos deja de pasar, a lo que nos dicen y a los que decimos, a lo que nos duele, a lo que sentimos, a lo que no podemos. Todo esto lo denomina ella «cieno de temores, de pusilanimidad y cobardía», del que difícilmente saldremos por nosotros mismos. Sin embargo, poniendo los ojos en Cristo «nuestro entendimiento y voluntad se hace más noble y más aparejado para todo bien tratando a vueltas de sí con Dios».

\section{Amor al prójimo}

Dice Teresa que al amor le han usurpado el nombre, y algo que pierde el nombre pierde poco a poco su identidad, se diluye y termina por ser irreconocible. Por eso ella quiere antes aclarar los términos. No se trata de sentimentalismo, este se acaba ahogando en sus propias redes y es como la semilla que cae al borde del camino, que no tiene la fuerza ni las condiciones para dar fruto. Es este un amor falso que nos hace buscar solamente nuestra propia satisfacción, que se 
mueve solo por el gusto, la apetencia y el deseo de ser recompensado de alguna manera. Se cierra en sí mismo y suele ser excluyente, sin abrirse a nadie más acaba pudriéndose y haciéndonos esclavos, nos roba toda libertad.

Teresa, que conoce bien todos estos peligros nos habla de las señales de lo que ella llama el amor perfecto, reconociendo que nunca acabamos de guardarlo del todo. Este amor es propio de «almas generosas... aficionadas a dar mucho más que a recibir..., que no se les da más ser queridas que no..., y ninguna cosa se les pone por delante por el bien de aquel alma» (C 6, 7-8).

Santa Teresa introdujo un elemento nuevo de la Vida Religiosa de su tiempo: las monjas debían tener dos horas diarias en las que todas juntas compartiesen en un clima distendido y de confianza, el mismo tiempo que asigna para la oración personal. Estas relaciones, que ella denominó como recreación, tienen una estructura claramente circular, donde todas sentadas en círculo se ven, se hablan y se escuchan, donde no hay puestos de dignidad, todas son iguales: «todas se han de querer, todas se han de ayudar» (C 4, 7).

Es aquí, en este terreno de las relaciones, donde hay que vigilar especialmente la «cocción» de nuestro sustento espiritual. No en los rincones, sino en medio de las ocasiones, dice Teresa, donde se verifica nuestra evolución y si nuestros deseos, propósitos y proyectos van cobrando fuerza y se van concretando o, si por el contrario, son algo tan crudo que aun no se puede digerir.

Se trata, por tanto, de conocerse, de ir creciendo juntos, de caminar hacia la madurez de la comunión, donde todos somos «uno». Y esto nos lleva a concebir una mesa de inclusión, a la que todos estamos invitados, en la que cada uno tiene su puesto y en la que nadie sobra.

Si Dios es Padre, los hijos hemos de vivir como hermanos. Tenemos vocación de fraternidad y esto es para todos. La vida en sí no es un asunto individual por más que nos empeñemos en ello, la historia de cada persona no tiene sentido si no se comparte. Este misterio no nos deja escapar de esta vocación de ser hermanos. Nos somete, a los que en principio somos extraños, a una relación obligatoria, a una acogida de lo distinto (cada uno tiene un origen familiar, cultural, social y generacional distinto del que pueden tener los otros), también a una acogida de lo incomprensible (si no nos acabamos de conocer, de comprender a nosotros mismos en nuestras incoherencias, contrastes... ¿cómo vamos a querer que sea fácil entender, comprender a los otros?).

La fraternidad, por tanto, se configura como acogida del extraño, del distinto, del incomprensible. Se nos da un proyecto común y ahí nos encontramos, enfrentándonos siempre a una cierta tensión positiva porque nos vemos obligados a que nuestra distinción conviva con la de los otros allá donde vayamos. Esto hace que las relaciones no sean algo del todo natural, y aquí la diferencia de una familia con vínculos de sangre. Nuestras relaciones se aprenden a realizar. Aprendemos también que esta situación de incomprensibilidad que no se ajusta del todo a nuestra lógica apunta a la incomprensibilidad de Dios, a quien nos tenemos que 
confiar sin entenderlo del todo. Y sólo hay una forma de salvar esto: confiar. Es la disciplina de la confianza cuando llegan los distintos y los distantes a nosotros mismos. Sabiendo siempre que nos pertenecemos unos a otros como bendición.

El lugar donde se construye esta relación y con la que queremos ser signo del mundo nuevo no es otro que el amor en la imperfección. El mundo no es algo unitario, la armonía a la que aspiramos siempre sólo se dará en el Reino de los cielos. Los dos polos tienen que existir siempre: la tensión al proyecto común y la distinción que revela mis propios límites o demonios, esto es: el mundo no es exactamente como nosotros lo vemos y lo queremos.

Para Teresa, este es el amor perfecto. Si el conocimiento propio es como el pan que acompaña los demás alimentos, el amor es como la sal que da sabor a todo, que nos hace gustar el ir juntos: «No hay cosa enojosa que no se pase con facilidad en los que se aman y recia ha de ser cuando de enojo» $(C 4,5)$.

\section{Desasimiento de todo lo creado}

Desasirse es despegarse, soltarse, no agarrarse a nada ni a nadie ni a nosotros mismos. Pero esto no resulta fácil, porque lo cierto es que el hombre se agarra a mil cosas como a un clavo ardiendo. Vivimos muy agarrados a nuestros bienes materiales, asegurándolos lo más posible, siempre con miedo a perderlos, igual que el joven rico, que estaba dispuesto a todo menos a soltarse de su riqueza. Nos agarramos al afecto de los otros como una lapa, a su reconocimiento, a su estima, a su parecer. Así estaba la samaritana, bien asida al cántaro de sus afectos nunca saciados. Nos agarramos, cómo no, a nosotros mismos, a nuestra concepción de la vida, a nuestros esquemas mentales, a nuestra falsa seguridad y acabamos huyendo, como Jonás, de un sitio a otro, para no oír la llamada a lo que es nuestra verdadera misión en la vida.

Así, agarrados, nos hacemos la idea de no caer en ningún vacío existencial. Porque de lo que tenemos miedo en el fondo es de quedarnos sin un asidero que nos libre del sinsentido y la nada. Nos da la sensación de que si nos soltamos no haremos pie, no habrá seguridad, y ¿qué será de nosotros? ¿Quién nos salvará?

El desasimiento tiene mucho que ver con la fe, con la confianza de saber que no necesitamos agarrarnos a ningún clavo ardiendo, pues somos ya seres sostenidos por un amor eterno. Desde esta premisa podemos entender que el soltarse o desasirse no es algo negativo y arriesgado, sino todo lo contrario, es lo mejor que nos puede suceder para encontrar la verdadera firmeza.

La persona que se atreve a iniciar este camino espiritual hacia su propio corazón, la que ha empezado a trabajar en el huerto de su interioridad adquiere la sabiduría del «sólo Dios basta», que nos enseña Teresa. Es a fin de cuentas apuntar a la libertad más alta, poder gozarlo todo sin enredarnos con nada.

Al igual que el árbol deja caer sus hojas en el otoño y no las retiene para sí, dejando que la vida fluya sin más, con la esperanza de una nueva primavera, nosotros hemos de entender así el desasimiento, más que una renuncia es una 
actitud de receptividad: se deja caer todo eso a lo que nos agarramos como un salvavidas en medio de nuestros miedos para poder recibir la mano que verdaderamente nos sostiene. Nos desasimos para bendecir, para que sea revelada la verdad de las cosas, de las personas, del mismo Dios.

El desasimiento también nos posibilita el estar disponible, abiertos al Dios que nos sorprende siempre en cada misión que se nos encomienda. Nos lleva de la ambición al desprendimiento; del consumo al sano disfrute de las cosas; del estado de bienestar al estado de compartir, de la depredación a la sobriedad.

Teresa, con sentido práctico, nos dice que no está la solución en huir del mundo en que estamos sino «en que determinadamente se abrace el alma al buen Jesús, Señor nuestro, que como allí lo halla todo, lo olvida todo» $(C 9,59)$.

Ella, que es monja y que habla a sus hijas, apartadas en el convento, les dice que esto del desasimiento es una batalla que se libra en el corazón y que ellas no la tienen ganada por el hecho de haber renunciado libremente a algunas cosas: "¡Oh hermanas mías!, no os aseguréis ni os echéis a dormir, que será como el que se acuesta muy sosegado habiendo muy bien cerrado sus puertas por miedo a los ladrones, y se los deja en casa. Y ya sabéis que no hay peor ladrón, pues quedamos nosotras mismas» (C 10,1).

La clave para Teresa está ahí: quedar fascinados por el amor, la belleza, la verdad de Cristo, para poder soltarnos de esos otros asideros engañosos y nada seguros, para asirnos a solo Él:

\author{
En Cristo mi confianza \\ y de Él solo mi asimiento, \\ en sus cansancios mi aliento, \\ en su imitación mi holganza \\ Aquí estriba mi firmeza, \\ aquí mi seguridad, \\ la prueba de mi verdad, \\ la muestra de mi fineza (P 25).
}

\title{
La humildad
}

Este es el ejercicio principal de oración, dice Teresa, andar en verdad delante de Dios y de los hombres. Alcanzar el mayor grado de coherencia entre lo que se piensa, lo que se dice y lo que se hace, sin caer en el juego de las apariencias.

Es un ingrediente que no puede faltar, y sin embargo cada vez resulta más raro encontrarlo en esta mentalidad nuestra en la que todos queremos ser importantes, grandes, y no quedarnos atrás, porque los que se quedan atrás, según nuestra lógica, no valen para este mundo competitivo, no son nadie.

Hemos concebido la humildad como algo que nos rebaja, que nos reduce y nos vuelve apocados y un tanto cobardes. Creemos que ser humildes es no atreverse a nada, esconderse en un rincón, encogernos ante nuestros fallos y límites y pensar que no servimos para nada. Toda esta concepción la desenmascaró la 
santa llamando «almas cobardes con amparo de humildad» (V 13, 2). «Por eso digo, hijas, que pongamos los ojos en Cristo, nuestro bien, y allí deprenderemos la verdadera humildad y ennoblecerse ha el entendimiento, y no hará el propio conocimiento ratero y cobarde» $(1 \mathrm{M} 2,11)$.

Nos olvidamos con frecuencia que la humildad es una fuerza en nuestra vida que nos va abriendo paso y nos conduce directamente a la presencia de Dios. ¿Qué hay realmente más elevado que estar delante de Dios? La humildad, por tanto, lejos de rebajarnos nos engrandece y también nos llena de gozo. El verdadero humilde es el que sabe cantar las maravillas que Dios hace en él, como nos enseña María en el Magníficat.

Cuando la humildad nos lleva ante Dios podemos vernos tal como somos, todos nuestros escondrijos van siendo iluminados por su verdad, pero a la vez vamos experimentando como nunca su misericordia. Esta es la señal de la verdadera humildad, que siempre trae consigo la paz y no la turbación.

Teresa sabe que quien no camina en esta verdad ni se abre a esta luz que nos desnuda, realmente no podrá avanzar en este viaje interior: «Espíritu que no vaya comenzando en verdad, yo más lo querría sin oración» $(C 4,4)$. Esto es por la sencilla razón de que el humilde se sabe tan pequeño, tan vulnerable, que su fuerza es Dios y no las débiles defensas que se fabrica el orgullo.

La humildad por otra parte va desalojando de nosotros todo sentimiento de autocomplacencia, todo pensamiento de que hemos conseguido esto o aquello por nuestros propios méritos. A medida que vamos avanzando en este camino descubrimos que todos esos dones, esas habilidades naturales de las que estábamos orgullosos, todos nuestros logros que un día creímos poseer fueron recibidos gratuitamente. La humildad nos va protegiendo del peligro de la presunción y de la temeridad. Ella es la raíz de toda vida espiritual que se va extendiendo en las profundidades de nuestro corazón: «Como este edificio todo va fundado en humildad, mientras más llegaos a Dios, más adelante ha de ir esta virtud y si no, va todo perdido» $(\mathrm{V} 12,4)$.

Ella es la esencia, que aunque es nombrada por Teresa la última virtud, a la postre, como dice ella, es sin embargo «la principal y las abraza a todas». Por que el amor sin humildad se acaba convirtiendo en egoísmo, la esperanza sin ella nunca alcanza lo que espera. En fin, si la humildad es la verdad todas las otras virtudes sin ella resultan falsas.

\section{LOS PUCHEROS DE LA VIDA COTIDIANA}

Tras habernos puesto al cuidado de nuestro huerto interior, tras contar con unos ingredientes muy específicos que Teresa nos recomienda, hemos de empezar a buscar los moldes en los que vivir todo eso que vamos descubriendo.

Lo primero es tener claro que la espiritualidad no es algo privado para sentirnos mejor. No es una práctica relajante que me hace olvidar lo que está pasando 
fuera de mí. Los «pucheros» representan nuestras tareas cotidianas, acaso nimias y tediosas, y que, por eso mismo, no solemos amar. Esas cosas que hemos de hacer y nos aburren, a las que no damos importancia y que deseamos dejar pronto por tener la sensación de que nos quitan nuestro precioso tiempo, pero que al fin y al cabo constituyen lo que es nuestro vivir cotidiano.

También en los ámbitos más desacralizados acaba colándose Cristo, que anda entre nosotros. Por eso dice Teresa a sus monjas, que «entre los pucheros anda el Señor» $(F 5,8)$ y no solo cuando van a la capilla a rezar, porque «el verdadero amante en toda parte ama y siempre de acuerda del amado» $(F 5,16)$.

Ahora esta cotidianidad queda iluminada desde nuestro interior por «una luz tan diferente» (cf. V 28, 5) y es cuando la mirada se transforma para poder ver que también entre nuestros «pucheros» anda Cristo, el amigo. Una amistad que ciertamente no se cierra en una actividad intelectual sino que es algo concreto, corpóreo, con todo lo que conlleva de reciprocidad y que se va construyendo a base de miradas pues «no está aguardando otra cosa, sino que le miremos...» (C 26, 3); que se alimenta a base de encuentros, «tratando muchas veces a solas» ( $\mathrm{V} 5,8)$; que se fortalece a base de esperas silenciosas y de gestos, «Marta y María han de andar siempre juntas»².

Solo desde este amor personal podremos dar el salto de vivir un cristianismo tal vez apático, centrado en la norma, a lo que puede ser el inicio de una vivencia mística, donde podemos abrirnos al asombro de un Dios que hace cosas grandes en medio de nuestra vida cotidiana, bendecida y querida por él.

Una espiritualidad en movimiento. Nuestro modo de estar en el mundo implica sobre todo el vínculo que podemos establecer entre nosotros y la historia a la que pertenecemos. El hecho de haber visitado nuestro yo más íntimo y de descubrir que es zona habitada por Dios nos remite, paradójicamente, hacia el mundo que nos rodea, pues todo el que se encuentra con el Resucitado sabe que tiene que ir a sus hermanos.

En base a esto, Teresa nos brinda una espiritualidad en movimiento que sale de los rincones y se abre paso por los caminos. Una espiritualidad que se deja afectar, cuestionar por los acontecimientos actuales y busca cómo responder. Ella enseña a sus monjas a implicarse del todo en la historia y les hace ver que tienen en ella un papel importante que desempeñar, llegando a sus raíces enfermas, identificándose con lo más nuclear del hombre, de la sociedad y permaneciendo ahí, sin escaparse a otros mundos de la fantasía, para combatir y padecer solidariamente, para caminar codo con codo con el que sufre y es explotado, colaborando de esta manera en la expansión del reino de Dios: "Ya, hijas, habéis visto la gran empresa que pretendemos ganar» $(C 4,1)$.

2. Cf. $7 \mathrm{M} \mathrm{4,} \mathrm{12:} \mathrm{«Marta} \mathrm{y} \mathrm{María} \mathrm{han} \mathrm{de} \mathrm{andar} \mathrm{juntas} \mathrm{para} \mathrm{hospedar} \mathrm{al} \mathrm{Señor,} \mathrm{y} \mathrm{tenerle}$ siempre consigo, y no le hacer mal hospedaje no le dando de comer». Teresa invita a integrar las dos dimensiones de la persona, activa y pasiva. 
Su encuentro personal con el Dios vivo, lejos de ensimismarla, de hacerla llevar una vida conformada con los gozos y penas de una intimidad inmune al exterior, le hace abrir bien los ojos y contemplar la realidad concreta que la rodea, ver cómo arde el mundo con la leña de sus tensiones sociales, políticas y religiosas. Ella no puede en modo alguno quedarse ahí mirando estas llamas, mientras «ve a este, su Señor, que tan apretado le traen». Identifica enseguida a Cristo, presente en su vivencia personal, con la Iglesia, su cuerpo que sufre la división interna. Consciente y dolida por este problema busca en qué puede ayudar y servir: «En este tiempo vinieron a mí noticia de los daños de Francia y el estrago que habían hecho estos luteranos... Diome gran fatiga, y como si yo pudiera hacer algo o fuera algo, lloraba con el Señor y le suplicaba remediase tanto mal. Paréciame que mil vidas pusiera yo para remedio de un alma...Y como me vi mujer y ruin, e imposibilitada de aprovechar en lo que yo quisiera en el servicio del Señor, y toda mi ansia era, y aún es, que pues tiene tantos enemigos y tan pocos amigos, que ésos fuesen buenos, determiné a hacer eso poquito que era en mí, que es seguir los consejos evangélicos con toda la perfección que yo pudiese y procurar que estas poquitas que están aquí hiciesen lo mismo» $(C 1,2)$.

Teresa de Jesús, la misma que nos encamina hacia la profundidad del castillo interior, nos enseña a sensibilizarnos con las necesidades de nuestro mundo para disponernos a hacer eso poquito que es en cada uno. La oración deja entonces de ser solo una vivencia íntima, una devoción personal, para abrirnos a un horizonte de comunión y compromiso: «Esto quiero yo, mis hermanas, que procuremos alcanzar, y no para gozar, sino para tener estas fuerzas para servir: deseemos y nos ocupemos en la oración» $(7 \mathrm{M} 4,12)$.

Sin embargo a la madre Teresa, a la que llamaron despectivamente inquieta $y$ andariega, no le estorbó la vida ni sus avatares para orar en todo momento y en toda circunstancia, porque nada era lo suficientemente grande o importante que le quitara la atención de aquel que amaba ${ }^{3}$. Para ella hay un criterio de discernimiento que no falla nunca: la oración es verdadera si esta nos cambia los planes, nos espolea, nos abre al hermano.

Una vez más nos está remitiendo a lo concreto, ayudándonos a no hacer «torres sin fundamento» $(7 \mathrm{M} 4,15)$, y esto se consigue con la compasión, que será el más excelente fruto de la oración contemplativa. Una compasión que no es solamente el sentimiento natural de pena cuando oímos noticias de alguna desgracia ocurrida en cualquier parte del mundo, sino dar alivio al enfermo que tenemos cerca, por ejemplo, «y si tiene algún dolor, te duela a ti... y que si vieres loar mucho a una persona, te alegres más mucho que si te loasen a ti... y cuando

3. F. Rivera, De la Vida de la Madre Teresa de Jesús: «No la causaba el camino distracción, ni la hacía más el andar que el estar, ni los negocios que la quietud, ni los trabajos que el descanso... Iba por el camino tan en oración y en la presencia de Dios que casi nunca la perdía y esto no como otras personas devotas, sino de un modo muy alto, que allá en lo más interior de su alma traía las tres Personas Divinas». 
viéremos alguna falta en alguna, sentirla como si fuera en nosotras y encubrirla» $(5 \mathrm{M} 3,11)$. Es cierto que en la medida en que oremos sentiremos cada vez más atracción por toda miseria humana para poder abrazarla y hacerla nuestra.

\section{Algunas CONCLUSIONES}

Lo que en definitiva viene Teresa a decirnos es que nuestra vida cotidiana con sus pequeños actos es muy valiosa a los ojos de Dios, y por pertenecerle a él está incorporada en todos sus detalles a un plan de salvación del que nosotros no tenemos plena conciencia. Las relaciones, tareas y actitudes que podamos tener resuenan en el mundo más de lo que nos imaginamos. Nada acontece, pues, sin que en cualquier circunstancia podamos hallar la rendija por la que asomarnos al misterio y ninguna experiencia es tan absolutamente personal e íntima que no tenga su repercusión hacia lo más concreto de la existencia compartida.

Es el mismo Señor el que le hace a la santa comprender todo esto remitiéndola a escenas tan básicas y ordinarias como es el comer y el dormir, siendo este el remedio para vivir con pleno sentido. Esto requiere una condición: todo lo que se haga sea por amor a él: "Yo estaba pensando cuán recio era el vivir que nos privaba de no estar así siempre en aquella admirable compañía, y dije entre mí: Señor, dadme algún medio para que yo pueda llevar esta vida. Díjome: Piensa, hija, cómo después de acabada no me puedes servir en lo que ahora, y come por mí y duerme por mí, y todo lo que hicieres sea por mí, como si no lo vivieses tú ya, sino yo» (CC 42, Sevilla, 1575).

La oración como trato de amistad nos rehace en nuestras heridas más profundas como personas sanas y sanadoras para un mundo necesitado de nuestra compasión. Esta «gran empresa que pretendemos ganar» empieza en la fuente de vida que brota en nuestro interior y continúa al retornar de ella con la mirada transformada por un amor que nos sostiene y nos hace vivir pendientes de él.

Hay hambre de pan, pero también de justicia, de cultura, de paz, de vida interior. Jesús vuelve a decirnos que demos nosotros de comer a tanta gente. Nos asustamos porque es demasiada el hambre y las bocas también son demasiadas para tan poco como podemos hacer. Pero Él no nos pide más que los cinco panes y dos peces que tenemos. Pide nuestra disposición, nada más. 